\title{
Effects of Ventilation on the Compartment Enhanced Mass Loss Rate
}

\author{
C.M. FLEISCHMANN \\ University of Canterbury \\ Christchurch, New Zealand
}

\author{
A.R. PARKES \\ New Zealand Fire Service \\ Christchurch, New Zealand
}

\begin{abstract}
This paper describes a series of pool fire experiments in a $1 \mathrm{~m}$ by $1.5 \mathrm{~m}$ by $1 \mathrm{~m}$ compartment. A single rectangular opening was used for the ventilation with opening factors ranging from 0.0039 to 0.071 . Fuel mass as a function of time was recorded to determine the effects of ventilation on the mass loss rate. The vent inflow and outflow were calculated from the temperature profiles within the compartment and ventilation opening. Results indicate that the global equivalence ratio is approximately constant at 1.7 over the range of opening factors investigated for vents with the $\mathrm{H}_{0} / \mathrm{W}_{0}<8$. When the $\mathrm{H}_{0} / \mathrm{W}_{\mathrm{o}}>12$ the global equivalence ratio is closer to 3. These results have practical application in zone models in which the compartment enhanced mass loss can be estimated from the ventilation opening in the compartment.
\end{abstract}

KEYWORDS: compartment fire, ventilation limited, mass loss rate, zone modelling

\section{INTRODUCTION}

In today's performance based code environment, more and more engineers are using compartment fire models for hazard evaluation. Typically, the practising engineer uses a zone model. This is due to the low cost, availability, and easy use of such models. Zone models rely on the user to input a burning rate to simulate the expected fire scenario. Generic $\mathrm{t}$-squared $\left(\mathrm{t}^{2}\right)$ fire growth rates have been adopted by many engineers for the design purposes. Originally developed for detection modelling, the $t^{2}$ growth rates come from experimental results with different fuel packages burning in the open.

These idealised growth rates may be appropriate for the early stages of compartment fires such as for detection modelling. However, as the fire continues to grow, the effects of the compartment cannot be ignored. The compartment can influence the burning rate in many 
ways, the most obvious are increased mass loss rates due to radiant feedback and reduced burning due to limited ventilation.

At the present time, the compartment enhanced mass loss rate is not accounted for in common zone models. In CFAST, the user specifies the burning rate based on engineering judgement. It is possible for the user to specify a burning rate well beyond any physical limits, giving results which under predict the temperature and may be completely unreasonable. Fire Simulator, a single room zone model found in FPETOOL, relies on a user input burning rate up to flashover and then switches to a burning rate that is estimated based on the exposed surface area, uniform heat flux, and heat of vaporisation. Fire Simulator does not account for any effect on the fuel mass loss rate based on limited ventilation.

The effects of ventilation on compartment fires was first recognised by Kawagoe ${ }^{1}$ and is now commonly found in the literature as:

$\dot{\mathrm{m}}_{\mathrm{Air}}=0.5 \mathrm{~A}_{\mathrm{O}} \sqrt{\mathrm{H}_{\mathrm{O}}}$

where 0.5 can range from 0.40 to $0.61 \mathrm{~kg} / \mathrm{s} \cdot \mathrm{m}^{5 / 2}$ depending on the discharge coefficient of the opening factor ${ }^{2}$. This relation is typically applied to post-flashover fires and can be used to estimate the heat release rate within the boundaries of the compartment by multiplying by the stoichiometric mass ratio, $r$. The actual mass loss rate of the fuel may be greater than this as is demonstrated by flames burning outside the compartment openings.

This paper describes recent experiments at the University of Canterbury to investigate the compartment effects on the fuel mass loss rate. A series of compartment fires using pool fires are discussed and the results presented. Results are compared with the closed form version of COMPF2 to determine how well a simple model can predict the temperatures over a wide range of opening factors. The primary goal of this work was to develop an engineering approximation for estimating the compartment effects on the fuel mass loss rate for use in zone models.

\section{BACKGROUND}

Burning liquid fires have been studied extensively. It has long been known that the burning rate of pool fires is controlled by the heat transfer back to the surface. For pool fire sizes of interest to fire engineers, i.e. diameters greater than $0.2 \mathrm{~m}$, the heat transfer is governed by the radiation back to the surface. For pool fires with diameters between $0.2 \mathrm{~m}$ and $1 \mathrm{~m}$ the flame is considered to be optically thin whereas pool fires greater than $1 \mathrm{~m}$ diameter the flame is optically thick ${ }^{3}$. The burning rate for pool fires greater than $0.2 \mathrm{~m}$ can be estimated using the following semi-theoretical expression ${ }^{4}$

$\dot{\mathrm{m}}_{\mathrm{f}}=\dot{\mathrm{m}}_{\infty}^{\prime \prime}[1-\exp (-\kappa \beta \mathrm{D})] \mathrm{A}_{\mathrm{P}}$

When a pool fire is placed in a compartment, the radiation to the fuel surface is increased as the upper layer and compartment boundaries radiate back to the pool. For pre-flashover fires, 
the radiation feedback to the fuel will increase slightly as the fire grows and the upper layer temperature increases. After flashover, radiation feedback is significantly increased and can drive the mass loss rate several times larger than the open air freeburning mass loss rate. Pool fire mass loss rates in post-flashover compartments has been studied by Babrauskas et. al. ${ }^{5}$ The increased mass loss rate is governed by the compartment temperature, as shown in the following relationship for the mass loss rate:

$\dot{\mathrm{m}}_{\mathrm{f}}=\frac{\varepsilon \sigma\left(\mathrm{T}_{\mathrm{f}}^{4}-\mathrm{T}_{\mathrm{b}}^{4}\right)}{\mathrm{h}_{\mathrm{f}}}$

The solution to Eq. 3 requires a solution for the compartment temperature in addition to the mass loss rate. The solution to the series of equations is coupled and strongly dependent on the compartment ventilation, conduction through the walls, and other heat loss terms. To solve this complex problem, the computer model COMPF2 can be used. COMPF2 solves for the compartment temperatures based on a single zone well stirred reactor assumption allowing for variable ventilation openings and conduction through the walls. A subroutine that predicts the enhanced burning rate of pool fires in compartments based on the radiative heat transfer back to the pool is one option within the program ${ }^{6}$. A closed form version of COMPF2 incorporating pool fires can also be found in the literature ${ }^{7}$. As part of this research, the closed form approximation of COMPF2 is compared with the experimental results.

At the opposite end of the scale from post-flashover fires are the pool fires burning near extinction. When a pool fire in a compartment is near extinction due to a lack of oxygen, the fire will oscillate. Under the right ventilation conditions, the oscillatory behaviour is stable ${ }^{8}$. This oscillating behaviour has been studied by Gray, et. al. ${ }^{9,10}$ and has been shown to occur in any two step process where the first step is comparatively temperature independent (vent flow) and the second is highly exothermic and temperature sensitive (reaction rate). Under certain conditions, i.e., small ventilation openings and pan placed above the soffit, Sugawa et. al. " reported that the flame can detach from the pool and travel around the compartment seeking oxygen. This phenomenon has been termed a "ghosting flame". In between limits of fully developed post flashover fires and near extinction fires, 4 distinct regions have been identified and analysed by Takeda et. al. ${ }^{12,13}$. However, space restrictions prohibit a detailed review of this work.

A pool fire geometry represents a worse case in terms of radiation enhanced mass loss rate. The entire fuel surface sees the hot upper layer and bounding surfaces. More complex fuels such as furniture or wood cribs will be partially shielded from the compartment environment and therefore less radiation will reach the fuel surface.

In this study, experiments were conducted over a wide range of opening factors from postflashover to extinction, with an emphasis on the region just beyond the oscillating phase. A $0.2 \mathrm{~m}$ diameter pan was chosen to allow the free burning mass loss rate to be governed by radiation where the radiation from the flame would be optically thin thereby maximising any compartment enhanced effects. 


\section{EXPERIMENTAL APPARATUS AND PROCEDURE}

Apparatus: Experiments were conducted in a $1.0 \mathrm{~m}$ wide by $1.5 \mathrm{~m}$ long by $1.0 \mathrm{~m}$ high compartment specifically designed for experiments near extinction i.e. fire burning under severely ventilation limited conditions. Figure 1 is a sketch of the compartment showing the experimental set-up and locations of the instrumentation. With exception of the floor, the interior surfaces of the compartment were lined with three layers of a $25 \mathrm{~mm}$ thick refractory fibre blanket installed over a $20 \mathrm{~mm}$ layer of calcium silicate board and $20 \mathrm{~mm}$ layer of gypsum wallboard. The floor was constructed with two $20 \mathrm{~mm}$ layers of calcium silicate board over a $20 \mathrm{~mm}$ layer of gypsum wallboard.

Ventilation into the compartment was modelled as a conventional window. A fixed maximum window size of $0.5 \mathrm{~m}$ square was located centrally within one of the $1 \mathrm{~m}$ by $1 \mathrm{~m}$ walls. Figure 1 shows the ventilation opening which was constructed of a $20 \mathrm{~mm}$ sheet of calcium silicate board. To be able to reduce the size of the ventilation opening, sliding panels were fixed either side of the opening to allow the ventilation to be varied both horizontally and vertically.

A heptane pool fire $0.2 \mathrm{~m}$ diameter and $35 \mathrm{~mm}$ high, was used in all of the experiments. The pan was placed in the rear of the compartment with the heptane supplied from a header tank to maintain a constant fuel surface height. Details of the experimental apparatus can be found in ref. 14.

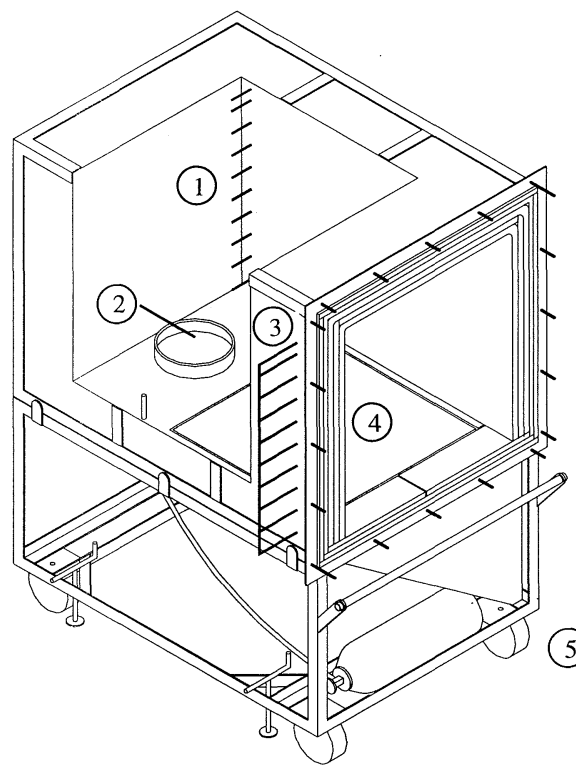

1. Rear Thermocouple Tree

2. Fuel Pan Thermocouple

3. Front Thermocouple Tree

4. Pressure Relief Panel

5.Vent Thremocouple Tree

6. Sliding Vent Panels

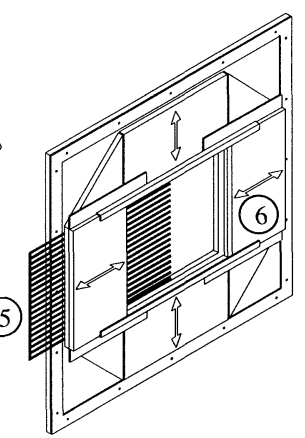

FIGURE 1. - Sketch of the experimental apparatus showing the experimental set-up and locations of instrumentation. 
Instrumentation: To measure the compartment gas temperatures, two vertical thermocouple trees were placed within the compartment, one at the front and one at the rear, as shown in Fig 1. Two sets of 10,1.6 mm diameter type K stainless steel clad thermocouples were installed at $100 \mathrm{~mm}$ vertical spacing. Thermocouples were placed $100 \mathrm{~mm}$ off the wall and $50 \mathrm{~mm}$ from the floor and ceiling. A single thermocouple was placed $20 \mathrm{~mm}$ above the fuel pan to monitor the flame temperature. A third thermocouple tree was placed within the vent to record the vent flow temperatures. Twenty, $1.6 \mathrm{~mm}$ diameter type $\mathrm{K}$ stainless steel clad thermocouples were spaced $25 \mathrm{~mm}$ vertically starting $12.5 \mathrm{~mm}$ off the opening boundaries.

Ambient Conditions: As all of the experiments were conducted outside, a weather station was set up in close proximity to the compartment to measure and record the wind speed and direction as well as the ambient temperature.

Data Acquisition System: Data from each sensor was recorded using a 80486DX50 computer with an 8 channel multifunction analog and digital input/output board. Three 32 channel analog input multiplexors were connected to this system. A total of 51 thermocouple and 4 voltage channels were used. Samples were recorded 10 times a second and averaged over 5 seconds. The average value was then recorded on the computer.

\section{PROCEDURE}

Before each experiment, a three minute baseline was taken to record the initial conditions. A pilot flame ignited the heptane at time zero. The fire was allowed to continue for 90 minutes. Once the fuel was ignited, the ventilation opening was reduced to the predetermined size. Nine different opening geometries were used with opening factors ranging from $0.0039 \mathrm{~m}^{5 / 2}$ to $0.071 \mathrm{~m}^{5 / 2}$.

\section{DATA REDUCTION}

Vent Flows: The vent flow was calculated from the temperature data using the vent opening thermocouple tree and the thermocouple tree located inside the compartment in the corner nearest the opening. Although other methods are available ${ }^{15}$ which may produce greater accuracy, the temperature profiles were felt to give acceptable results for the vent flow. Bidirectional probes were considered to monitor the velocities and calculate the mass flow but were not used based on the small opening sizes of interest. A pressure measurement was also considered but was not used due to the small height of the compartment. It would have a low $\Delta \mathrm{P}$ and high signal to noise ratio.

The temperature data was analysed using the method outlined by Janssens et. al. ${ }^{16}$ The change in density within a compartment and the subsequent change in pressure, can be calculated as a function of the height, if the temperature profile measured inside the compartment is known. 
The vent flow into the compartment is calculated using the following relationship:

$\dot{\mathrm{m}}_{\mathrm{i}}=1563 \mathrm{C}_{\mathrm{i}} \mathrm{W}_{\mathrm{o}} \int_{\mathrm{z}_{\mathrm{db}}}^{\mathrm{z}_{\mathrm{n}}}\left[\frac{1}{\mathrm{~T}_{\mathrm{d}}\left(\mathrm{z}^{\prime}\right)} \int_{0}^{\mathrm{z}_{\mathrm{n}}}\left(\frac{1}{\mathrm{~T}_{\infty}}-\frac{1}{\mathrm{~T}_{\mathrm{i}}\left(\mathrm{z}^{\prime \prime}\right)}\right) \mathrm{dz}^{\prime \prime}\right]^{1 / 2} d \mathrm{~d}^{\prime}$

The Reynolds number for the inflow ranged from 5300 to 11000 which gives flow coefficient, $\mathrm{C}_{\mathrm{i}}=0.68^{17}$.

Similarly, the flow rate out of the compartment is equal to:

$\dot{\mathrm{m}}_{\mathrm{o}}=1563 \mathrm{C}_{\mathrm{o}} \mathrm{W}_{\mathrm{o}} \int_{\mathrm{z}_{\mathrm{n}}}^{\mathrm{z}_{\mathrm{dt}}}\left[\frac{1}{\mathrm{~T}_{\mathrm{d}}\left(\mathrm{z}^{\prime}\right)} \int_{\mathrm{z}_{\mathrm{n}}}^{\mathrm{z}_{\max }}\left(\frac{1}{\mathrm{~T}_{\infty}}-\frac{1}{\mathrm{~T}_{\mathrm{i}}\left(\mathrm{z}^{\prime \prime}\right)}\right) \mathrm{dz}^{\prime \prime}\right]^{1 / 2} \mathrm{dz^{ \prime }}$

For the outflow the Reynolds number ranged from 2700 to 5900 resulting in a flow coefficient, $\mathrm{C}_{\mathrm{o}}=0.77^{17}$.

Before a value for the mass flow can be found, the neutral plane height $\left(z_{n}\right)$ is required as one of the limits of integration.

Neutral Plane: The neutral plane is located using conservation of mass criteria. The mass balance equation used has the following form :

$\frac{\mathrm{dm}_{\mathrm{c}}}{\mathrm{dt}}=\dot{\mathrm{m}}_{\mathrm{i}}+\dot{\mathrm{m}}_{\mathrm{f}}+\dot{\mathrm{m}}_{\mathrm{o}}=0$

Equation (6), was integrated numerically using the experimental temperatures to solve for the neutral plane height $\left(z_{n}\right)$. Once $z_{n}$ was determined, the mass flow rates into and out of the compartment were calculated from Equations (4) and (5).

Global Equivalence Ratio: The global equivalence ratio for the compartment is calculated from the fuel mass loss rate, stoichiometric mass ratio and vent flow rate using the following relationship:

$\phi=\frac{\mathrm{r} \cdot \dot{\mathrm{m}}_{\mathrm{f}}}{\dot{\mathrm{m}}_{\mathrm{air}}}$

Where $\phi>1$ indicates a fuel rich condition and $\phi<1$ is fuel lean.

\section{EXPERIMENTAL RESULTS}

Free burning pool: In addition to the compartment experiments, a free burn test in the open was conducted to determine the free burn value for comparison with the compartment results. For the free burning case $\dot{\mathrm{m}}=0.0011 \mathrm{~kg} / \mathrm{s}$ which is 1.8 times greater than the value predicted 
using Eq. 1 ( $\dot{\mathrm{m}}=0.00063 \mathrm{~kg} / \mathrm{s})$. Constants for heptane $\left(\mathrm{C}_{7} \mathrm{H}_{16}\right)$

$\left(\dot{\mathrm{m}}_{\infty}^{\prime \prime}=0.101 \mathrm{~kg} / \mathrm{s}, \kappa \beta=1.1 \mathrm{~m}^{-1}\right)$ used in Eq. 1 were taken from reference (3).

Summary: The results of the 14 experiments are summarised in Table I. Column 1 gives the run number which refers to specific experiments. Columns $2-6$ characterise the opening by defining the physical dimensions for the openings as width, height, soffit height, opening factor, and opening height to width ratio, respectively. Mass flow rates for the inflow, outflow, and fuel are given in columns 7 - 9, respectively. The time average temperatures recorded over the steady burning period for the $\mathrm{TC}$ tree nearest the opening are presented in columns $10-12$ as the average of all $10 \mathrm{TCs}$, the top TC, and the bottom TC, respectively.

\begin{tabular}{|c|c|c|c|c|c|c|c|c|c|c|c||}
\hline $\begin{array}{c}\text { Run } \\
\#\end{array}$ & $\begin{array}{c}\mathbf{W}_{\mathbf{o}} \\
(\mathbf{m})\end{array}$ & $\begin{array}{c}\mathbf{H}_{\mathbf{o}} \\
(\mathbf{m})\end{array}$ & $\begin{array}{c}\text { Soffit } \\
(\mathbf{m})\end{array}$ & $\begin{array}{c}\mathbf{A}_{\mathbf{o}} \mathbf{H}_{\mathbf{o}} \\
\left(\mathbf{m}^{\mathbf{5}}\right)\end{array}$ & $\mathbf{H}_{\mathbf{o}} / \mathbf{W}_{\mathbf{o}}$ & $\begin{array}{c}\mathbf{m}_{\text {in }} \\
(\mathbf{k g} / \mathbf{s})\end{array}$ & $\begin{array}{c}\mathbf{m}_{\text {out }} \\
(\mathbf{k g} / \mathbf{s})\end{array}$ & $\begin{array}{c}\mathbf{m}_{\text {burncd }} \\
(\mathbf{k g} / \mathbf{s})\end{array}$ & $\begin{array}{c}\mathbf{T}_{\text {avg }} \\
(\mathbf{K})\end{array}$ & $\begin{array}{c}\mathbf{T}_{\text {top }} \\
(\mathbf{K})\end{array}$ & $\begin{array}{c}\mathbf{T}_{\text {bottom }} \\
(\mathbf{K})\end{array}$ \\
\hline \hline 1 & 0.20 & 0.50 & 0.75 & 0.0707 & 2.5 & 0.0334 & 0.0377 & 0.0043 & 1318 & 1321 & 1294 \\
\hline 2 & 0.13 & 0.50 & 0.75 & 0.0442 & 4.0 & 0.0251 & 0.0274 & 0.0023 & 1157 & 1174 & 1138 \\
\hline 3 & 0.13 & 0.50 & 0.75 & 0.0442 & 4.0 & 0.0250 & 0.0274 & 0.0024 & 1234 & 1230 & 1245 \\
\hline 4 & 0.13 & 0.38 & 0.63 & 0.0287 & 3.0 & 0.0207 & 0.0228 & 0.0021 & 1059 & 1085 & 1022 \\
\hline 5 & 0.06 & 0.50 & 0.75 & 0.0221 & 8.0 & 0.0124 & 0.0141 & 0.0017 & 999 & 1029 & 968 \\
\hline 6 & 0.13 & 0.25 & 0.50 & 0.0156 & 2.0 & 0.0119 & 0.0131 & 0.0012 & 884 & 917 & 856 \\
\hline 7 & 0.13 & 0.25 & 0.75 & 0.0156 & 2.0 & 0.0118 & 0.0130 & 0.0012 & 891 & 943 & 858 \\
\hline 8 & 0.06 & 0.38 & 0.63 & 0.0144 & 6.0 & 0.0103 & 0.0114 & 0.0011 & 887 & 920 & 861 \\
\hline 9 & 0.03 & 0.50 & 0.75 & 0.0110 & 16.0 & 0.0058 & 0.0070 & 0.0012 & 849 & 885 & 824 \\
\hline 10 & 0.03 & 0.50 & 0.75 & 0.0110 & 16.0 & 0.0058 & 0.0069 & 0.0011 & 856 & 878 & 844 \\
\hline 11 & 0.06 & 0.25 & 0.50 & 0.0078 & 4.0 & 0.0059 & 0.0065 & 0.0007 & 777 & 809 & 763 \\
\hline 12 & 0.03 & 0.38 & 0.63 & 0.0072 & 12.0 & 0.0048 & 0.0057 & 0.0009 & 850 & 877 & 829 \\
\hline 13 & 0.03 & 0.25 & 0.50 & 0.0039 & 8.0 & Fire self extinguished without reaching a steady state phase \\
\hline 14 & 0.03 & 0.25 & 0.50 & 0.0039 & 8.0 & Fire self extinguished without reaching a steady state phase \\
\hline
\end{tabular}

TABLE 1 - Summary of the data from all 14 experiments giving opening geometry, mass flows, and time average temperatures.

All of the openings were vertical slots with the height greater than the width. Opening factors varied by more than an order of magnitude from the smallest $(0.0039)$ to the largest opening (0.071). Height to width ratio varied from 2.5 to 16 giving a broad range of opening geometries. In run \# 12, the smallest opening factor to reach steady state burning, the ventilation area to boundary surface area ratio of $1.5 \mathrm{E}-3$, would be considered a "very loose" construction as defined by Klote ${ }^{18}$.

Figure 2 shows the temperature history from the front TC tree for run number 12 in Table I. Temperatures are plotted for 5 of the 10 thermocouples starting $150 \mathrm{~mm}$ off the floor and spaced $200 \mathrm{~mm}$ apart. The legend shows the height of each thermocouple relative to the floor. The data is typical of runs 4 thru 12 and is used here to help describe the fire progression. For the first minute the temperature rises quickly as the pool fire becomes established. Once the burning is established on the pan, the flame enters into an oscillating phase where the flame moves around the pan and visibly pulses with the incoming air. The flame moves closer and closer to the opening until the flaming becomes stable in the opening. The pulsing phase is seen in figure 2 from 60 to 960 seconds. Once the flame stabilised in the opening, the fire 
continues to burn as long as the fuel is supplied. For run 12, shown in Fig. 2, the flame is stable in the opening approximately 960 seconds after ignition. With the stable flame in the opening, the compartment temperatures increase slightly over time as the bounding surfaces are heated. The long quasi-steady burning period is seen in Fig. 2 after approximately 960 seconds.

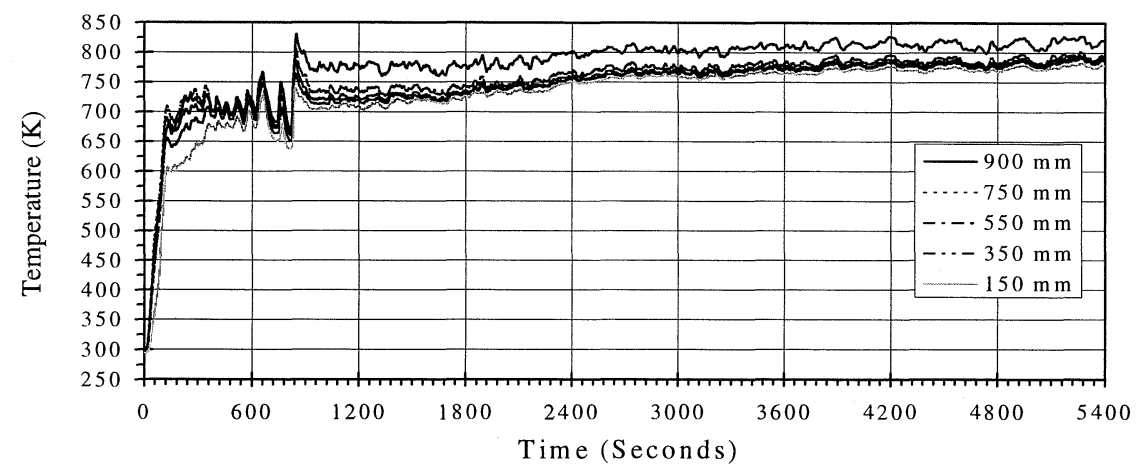

FIGURE 2 - Temperature history for the thermocouple tree closet to the opening. The legend gives the height of each respective thermocouple measured from the floor.

Figure 3 shows the flames at the opening for run \#5. The flame is stable at the opening with the neutral plane approximately at the mid height of the opening. Below the neutral plane flames can be seen immediately inside the opening indicating a very fuel rich environment within the compartment.

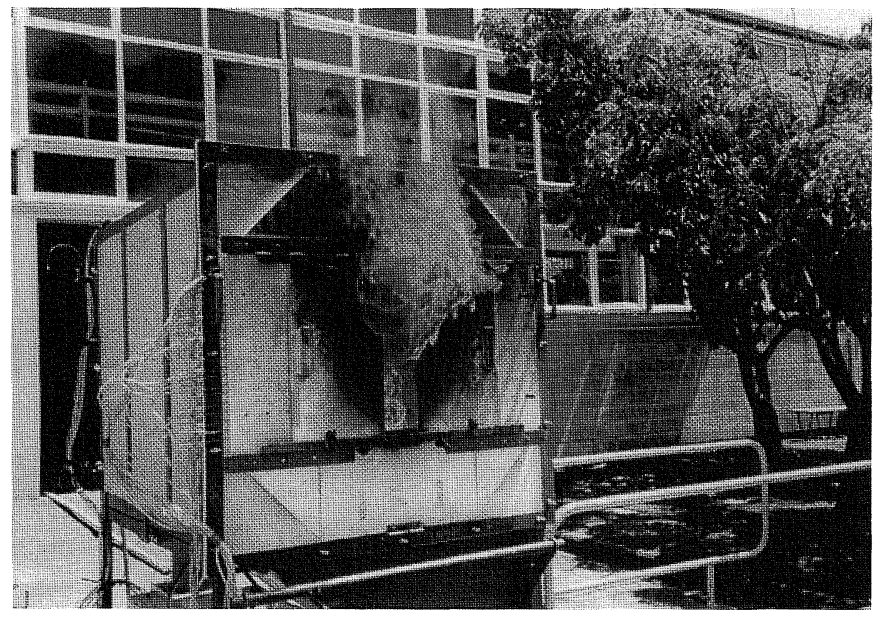

FIGURE 3 - Photograph showing the flames exiting the opening with the neutral plane located near the mid height of the opening. 
In runs 1 thru 3 the flame did not oscillate or move around the compartment. Rather the flames filled the entire compartment in a more classical post-flashover scenario. Temperature profiles for runs 1 thru 3 are much smoother than seen in Fig. 2.

Figure 4 shows the average compartment temperature versus the opening factor for the 12 runs that reached quasi-steady burning conditions. Experimental data $(\bullet)$ is compared with the closed form approximation for COMPF2 (+). The discontinuity in the COMPF2 results is due to the effects of different opening heights. Results from COMPF2 fit the general trend of the experimental data but have a much shallower slope than the experiments. Defining flashover as $500^{\circ} \mathrm{C}$, all of the runs that reached a quasi-steady burning were post flashover fires.

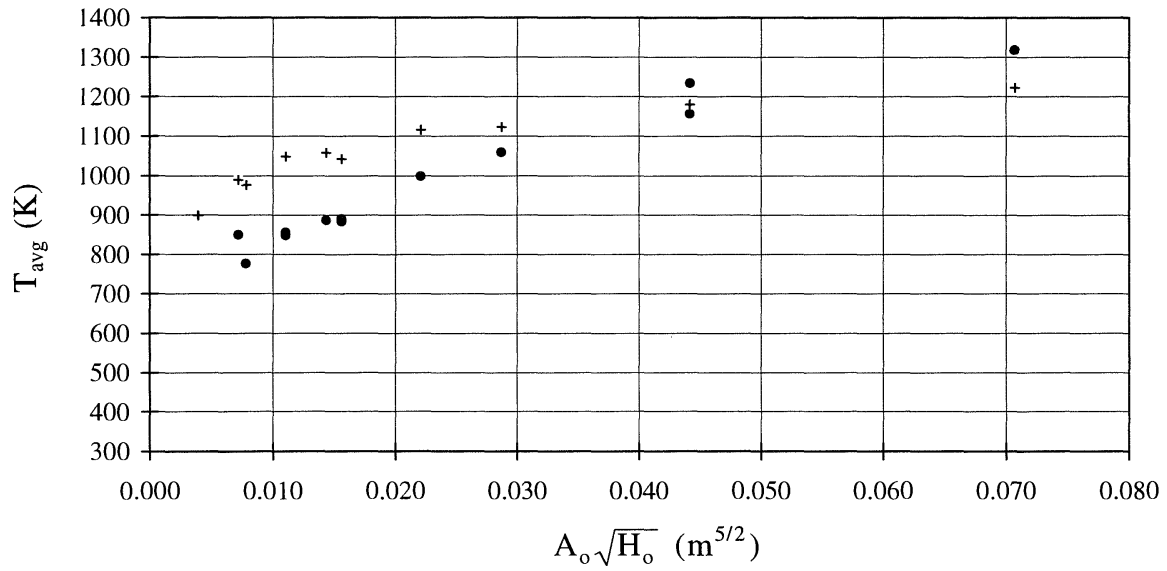

FIGURE 4 - The average steady state temperature versus opening factor. The experimental results $(\bullet)$ are compared with the closed form approximation of COMPF2 (+).

Figure 5 shows the global equivalence ratio versus opening factor for all twelve experiments. Equivalence ratio ranged from 1.4 to 3.2. The individual numbers shown at each data point indicate the $\mathrm{H}_{\mathrm{o}} / \mathrm{W}_{\mathrm{o}}$ ratio for the openings. When the $\mathrm{H}_{\mathrm{o}} / \mathrm{W}_{\mathrm{o}}>12$ the equivalence ratio was much higher than when $\mathrm{H}_{0} / \mathrm{W}_{0}<6$. Looking at the data for $\mathrm{H}_{0} / \mathrm{W}_{0}<8$ the average $\phi=1.7$.

Figure 6 is a plot comparing the inflow, calculated from the temperature profile, with $0.5 \mathrm{~A}_{\mathrm{o}} \sqrt{\mathrm{H}_{\mathrm{o}}}$. The data shows reasonable correlation with the $0.5 \mathrm{~A}_{\mathrm{o}} \sqrt{\mathrm{H}_{\mathrm{o}}}$ equation. A better fit to the data is obtained if the constant 0.5 were increased to 0.55 which is within the bounds given by Rockett ${ }^{2}$. 


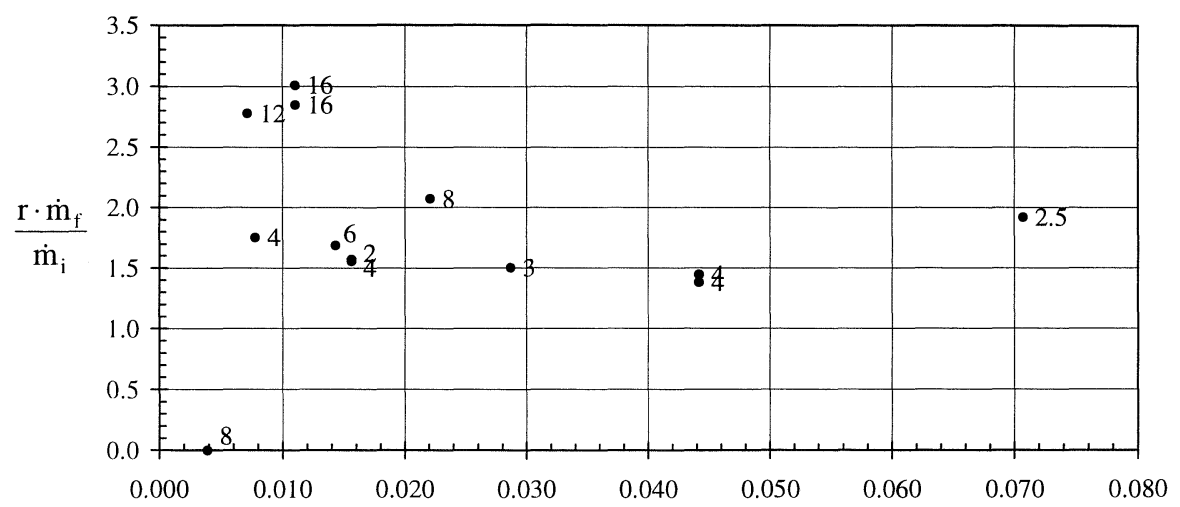

$\mathrm{A}_{\mathrm{o}} \sqrt{\mathrm{H}_{\mathrm{o}}}\left(\mathrm{m}^{5 / 2}\right)$

FIGURE 5 - Plot of the global equivalence ratio versus opening factor. Numbers adjacent to data point indicate the $\mathrm{H}_{0} / \mathrm{W}_{\mathrm{o}}$ ratio for the opening.

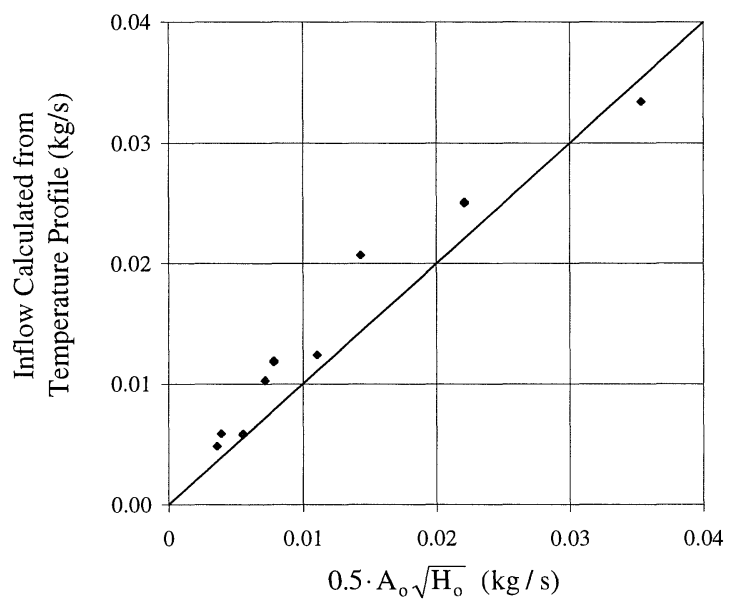

FIGURE 6 - Plot of the mass flow rate into the compartment calculated from the temperature data compared to the $0.5 \mathrm{~A} 。 \sqrt{\mathrm{H}_{\mathrm{o}}}$ correlation.

\section{CONCLUSIONS}

The results of this research shows that the compartment can have a significant effect on the fuel mass loss rate for small pool fires. The increase in mass loss rate due to radiation feedback was nearly 7 times greater than the freeburning case. 
For openings with $\mathrm{H}_{\mathrm{o}} / \mathrm{W}_{\mathrm{o}}<8$ the global equivalence ratio is relatively constant at $\phi=1.7$ over a wide range of opening factors. Even when the ventilation into the compartment was reduced to a level were the mass loss rate was below the free burning mass loss rate, the global equivalence ratio was approximately 1.7. This result may be of practical significance to the practising engineer using zone fire models. Knowing the size of the ventilation opening, the compartment enhanced burning rate can be estimated by multiplying the ventilation limited air flow rate by a factor of 2 . The value of 2 rather than 1.7 indicates the uncertainty in the value of the constant 0.5 in the $0.5 \mathrm{~A}_{0} \sqrt{\mathrm{H}_{\mathrm{o}}}$ correlation. Although there are only 3 data points with $\mathrm{H}_{\mathrm{o}} / \mathrm{W}_{\mathrm{o}} \geq 12$, there is a strong indication that global equivalence ratio will increase for such openings.

Future work should focus on ventilation opening with $\mathrm{H}_{\mathrm{o}} / \mathrm{W}_{\mathrm{o}} \geq 12$ to quantify the effects of a tall narrow opening. Openings with $\mathrm{H}_{\mathrm{o}} / \mathrm{W}_{\mathrm{o}} \leq 1$ should also be investigated. Additional fuels and pan sizes should be used to determine what effect the fuel geometry and composition have on the global equivalence ratio.

\section{ACKNOWLEDGEMENTS}

Authors are indebted to the New Zealand Fire Service Commission for their support of the Fire Engineering program at the University of Canterbury. The assistance of C. Caldwell, C. Grant, D. Green and I. Sheppard is appreciated.

\section{REFERENCES}

\footnotetext{
' Kawagoe, K. "Fire behavior in rooms", Report No. 27, Building Research Institute, Tokyo, 1958.

${ }^{2}$ Rockett, J. A., "Fire Induced Gas Flow in an Enclosure", Combustion Science and Technology, 12, 165-175, 1976.

${ }^{3}$ Babrauskas. V., "Burning Rates", The SFPE Handbook of Fire Protection Engineering, Section 3/Chapter 1, 2nd edition, 1995.

${ }^{4}$ Babrauskas, V., "Estimating Large Pool Fire Burning Rates”, Fire Technology, 19, $251,1983$.

${ }^{5}$ Babrauskas, V. and Wickstrom, U.G., “Thermoplastic Pool Compartment Fires", Combustion and Flame, 34, 195-201, 1979.
}

${ }^{6}$ Babrauskas, V., "COMPF2-A Program for Calculating Post-Flashover Fire Temperatures", NBS Technical Notes 991, National Bureau of Standards, 1979.

${ }^{7}$ Babrauskas V, “A Closed-form Approximation for Post-flashover Compartment Fire Temperatures", Fire Safety Journal, 4, 63-73, 1981.

${ }^{8}$ Kim, K.I., Ohtani, H., and Uehara, Y., "Short Communication - Experimental Study on Oscillating Behavior in a Small-Scale Compartment Fire", Fire Safety Journal, 22, 377-384, 1992. 
${ }^{9}$ Gray, B.F., Coppersthwaite, D.P., and Griffiths, J.F., "A novel thermal instability in a semi-batch reactor", Process Safety Progress, 12, 49-55, 1993.

${ }^{10}$ Gray, B.F., Coppersthwaite, D.P., and Griffiths, J.F., "Oscillatory reaction in a semi-batch reactor, The Journal of Physical Chemistry, 95, 6971-6977, 1991.

"Sugawa, O., Kawagoe, K, and Ogahara, I., "Burning Behavior in a Poorly-Ventilated Compartment Fire - Ghosting Fire", Fire Science and Technology, 9, 5-14, 1989

${ }^{12}$ Takeda, H. and Akita, K., "Critical Phenomenon in Compartment Fires with Liquid Fuels," $18^{\text {th }}$ Symposium (Int'l) on Combustion, The Combustion Institute, 519-527, 1981.

${ }^{13}$ Takeda, H. and Akita, K., "New Model of Liquid or Thermoplastic Pool Fires in Compartment," $19^{\text {th }}$ Symposium (Int'l) on Combustion, The Combustion Institute, 897-904, 1983.

${ }^{14}$ Parkes, A. R., "Under-Ventilated Fires”, University of Canterbury Fire Engineering Report No. 965, 1996.

${ }^{15}$ Emmons, H. W., "Vent Flows", The SFPE Handbook of Fire Protection Engineering, 2nd Edition, Section 2/Chapter 5, 1995.

${ }^{16}$ Janssens M. and Tran H. C., "Data Reduction of Room Tests for Zone Model Validation", Journal of Fire Sciences, 10, 528-555, 1992.

${ }^{17}$ Prahl, J. and Emmons, H. W., "Fire Induced Flow Through an Opening," Combustion and Flame, 25, 369-385, 1975.

${ }^{18}$ Klote, J H, "Smoke Control," The SFPE Handbook of Fire Protection Engineering, 2 nd Edition, Section 4/Chapter 12, 1995.

\section{NOMENCLATURE}

$\mathrm{A}=\operatorname{area}\left(\mathrm{m}^{2}\right)$

$\mathrm{C}=$ flow coefficient

$\mathrm{D}=$ pool diameter $(\mathrm{m})$

$\mathrm{H}=$ height of opening $(\mathrm{m})$

$\mathrm{h}_{\text {Fuel }}=$ heat of gasification $(\mathrm{J} / \mathrm{kg})$

$\dot{\mathrm{m}}=$ mass flow rate $(\mathrm{kg} / \mathrm{s})$

$\dot{\mathrm{m}}_{\infty}^{\prime \prime}=$ mass loss rate per unit area of a large pool diameter $\left(\mathrm{kg} / \mathrm{m}^{2} \mathrm{~s}\right)$

$\dot{\mathrm{q}}=$ hear release rate $(\mathrm{kW})$

$r \quad=$ stoichiometeric mass ratio fuel/air

$\mathrm{W}=$ width of opening $(\mathrm{m})$

$\mathrm{t}=$ time (s)

$\mathrm{T}=$ temperature $(\mathrm{K})$

$\mathrm{z}=$ height above the floor (m)

$\kappa \beta=$ extinction-absorption coefficient $\left(\mathrm{m}^{-1}\right)$

$\sigma=$ Stefan-Boltzman constant $\left(\mathrm{W} \mathrm{m}^{-2} \mathrm{~K}^{-4}\right)$

\section{Subscripts}

air $=$ air

$\mathrm{b}=$ boiling point

$\mathrm{c}=$ compartment

$\mathrm{db}=$ bottom of ventilation opening

$\mathrm{dt} \cdot=$ top of ventilation opening

$\mathrm{f}=$ fire

$\mathrm{i}=$ inside compartment / inflow

$\max =$ maximum

$\mathrm{n}=$ neutral plane

$\mathrm{o}=$ opening/out flow

$\mathrm{p}=$ pool

$\mathrm{r}=$ accumulated inside compartment

$\infty=$ ambient 